University of Nebraska - Lincoln

DigitalCommons@University of Nebraska - Lincoln

May 2000

\title{
Magnetic and structural properties of $\mathrm{SmCo7-x} \mathrm{Cu}_{\mathrm{x}}$ alloys
}

\author{
I.A. Al-Omari \\ University of Nebraska - Lincoln \\ Y. Yeshurun \\ Institute of Superconductivity and Department of Physics, Bar-Ilan University, Ramat Gan 52900, Israel \\ Jian Zhou \\ University of Nebraska - Lincoln \\ David J. Sellmyer \\ University of Nebraska-Lincoln, dsellmyer@unl.edu
}

Follow this and additional works at: https://digitalcommons.unl.edu/physicssellmyer

Part of the Physics Commons

Al-Omari, I.A.; Yeshurun, Y.; Zhou, Jian; and Sellmyer, David J., "Magnetic and structural properties of SmC07-xCux alloys" (2000). David Sellmyer Publications. 60.

https://digitalcommons.unl.edu/physicssellmyer/60

This Article is brought to you for free and open access by the Research Papers in Physics and Astronomy at DigitalCommons@University of Nebraska - Lincoln. It has been accepted for inclusion in David Sellmyer Publications by an authorized administrator of DigitalCommons@University of Nebraska - Lincoln. 


\title{
Magnetic and structural properties of $\mathrm{SmCo}_{7-x} \mathrm{Cu}_{x}$ alloys
}

\author{
I. A. Al-Omaria) \\ Behlen Laboratory of Physics and Center for Materials Research and Analysis, University of Nebraska, \\ Lincoln, Nebraska 68588-0111 \\ Y. Yeshurun \\ Institute of Superconductivity and Department of Physics, Bar-Ilan University, Ramat Gan 52900, Israel
}

J. Zhou and D. J. Sellmyer

Behlen Laboratory of Physics and Center for Materials Research and Analysis, University of Nebraska, Lincoln, Nebraska 68588-0111

We report the structural and magnetic properties of $\mathrm{SmCo}_{7-x} \mathrm{Cu}_{x}$, where $x=0,0.1,0.2,0.3,0.4$, 0.5, and 0.7. X-ray diffraction shows that these alloys from the disordered hexagonal $\mathrm{TbCu}_{7}$-type structure. For large values of $x(x \geqslant 0.8)$ the hexagonal $\mathrm{TbCu}_{7}$-type structure cannot be formed. $\mathrm{X}$-ray diffraction on magnetically aligned samples show that these samples have uniaxial anisotropy. The lattice parameters $(a$ and $c)$ are dependent on the $\mathrm{Cu}$ concentration, and the unit cell volume is found to increase with $x$. The saturation magnetization decreases with $x$ at both room temperature and $25 \mathrm{~K}$. The Curie temperature increases with $x$ for small values of $x$ while it decreases with $x$ for large values of $x$. A maximum value of $T_{C}=852{ }^{\circ} \mathrm{C}$ is found in these alloys. (c) 2000 American Institute of Physics. [S0021-8979(00)95108-9]

\section{INTRODUCTION}

In the last 30 years, there has been an intensive search for new iron-rich or cobalt-rich rare-earth intermetallic compounds for magnetic applications including materials for room temperature permanent magnets, high temperature permanent magnets, magnetic recording, etc. The compounds $\left(\mathrm{R}_{x} \mathrm{Fe}_{y} \mathrm{Co}_{z}\right)$ include materials with atomic ratios of rare-earth to iron and cobalt 1:5, 1:7, 1:12, and 2:17 with different types of structure. Most of the $\mathrm{R}-\mathrm{Fe}$ compounds have low Curie temperature $\left(T_{C}\right)$, relatively low saturation magnetization $\left(M_{s}\right)$, small magnetic anisotropy, in-plane anisotropy, and are unstable at high temperature which lowers their potential as materials for high temperature applications. ${ }^{1-7}$ The disordered $\mathrm{TbCu}_{7}$-type or so-called 1:7 structure shows interesting magnetic properties when Co or other elements are substituted for Fe.

The metastable $\mathrm{TbCu}_{7}$-type structure of $\mathrm{Sm}(\mathrm{Fe}, \mathrm{Ti})_{7}$ or $\mathrm{Sm}(\mathrm{Fe}, \mathrm{V})_{7}$ can be formed under certain preparation conditions. Saito et al. ${ }^{8}$ studied $\mathrm{SmFe}_{11} \mathrm{Ti}$ alloy ribbons and found that the structure changes from a tetragonal $\mathrm{ThMn}_{12}$-type structure to a hexagonal $\mathrm{TbCu}_{7}$-type structure by changing the roller velocity. They also found that ribbons with a $\mathrm{ThMn}_{12}$-type structure give the maximum hard magnetic properties. Xiao et al. ${ }^{9}$ studied the $\mathrm{Sm}-\mathrm{Fe}-\mathrm{Ti}$ system and found that this system crystallizes in the metastable $\mathrm{TbCu}_{7}$-type structure with an easy in-plane magnetization and has a $T_{C}$ of $243^{\circ} \mathrm{C}$. The metastable $\mathrm{TbCu}_{7}$-type structure transforms to a $\mathrm{ThMn}_{12}$ structure (with $T_{C}=305^{\circ} \mathrm{C}$ and easy in-plane magnetization) at an annealing temperature higher than $740{ }^{\circ} \mathrm{C}$. Katter et al. ${ }^{10}$ studied $\mathrm{Sm}-\mathrm{Fe}-\mathrm{N}$ and found that $\mathrm{Sm}_{10.6} \mathrm{Fe}_{89.4} \mathrm{~N}_{y}$ forms the $\mathrm{TbCu}_{7}$-type structure with a coer-

a) Permanent address: Dept. of Applied Physical Sciences, Jordan University of Science and Technology, PO Box 3030, Irbid, Jordan; electronic mail: ialomari@hotmail.com civity of $6.0 \mathrm{kOe}$, a remanence of $684 \mathrm{emu} / \mathrm{cm}^{3}$, and an energy product $(B H)_{\max }$ of 8.74 MGOe, while $\mathrm{Sm}_{12} \mathrm{Fe}_{88}$ crystallizes in the rhombohedral $\mathrm{Th}_{2} \mathrm{Zn}_{17}$ structure. This study also showed that $T_{C}$ and $M_{s}$ change from $200^{\circ} \mathrm{C}$ and 987 $\mathrm{emu} / \mathrm{cm}^{3}$ for $\mathrm{Sm}_{10.6} \mathrm{Fe}_{89.4}$ to $470{ }^{\circ} \mathrm{C}$ and $1114 \mathrm{emu} / \mathrm{cm}^{3}$ for $\mathrm{Sm}_{10.6} \mathrm{Fe}_{89.4} \mathrm{~N}_{y}$. A study of $\mathrm{R}-\mathrm{Cu}$ compounds by Buschow and Van Der Gast ${ }^{11}$ showed that for $\mathrm{R}=\mathrm{Gd}, \mathrm{Tb}$, Dy, and $\mathrm{Y}$ a compound of the approximate composition $\mathrm{RCu}_{7}$ can be formed with the $\mathrm{TbCu}_{7}$ structure and these compounds decompose with annealing at low temperatures into $\mathrm{RCu}_{5}$ and elementary $\mathrm{Cu}$. They also found that $c / a$ is about 0.84 for $\mathrm{RCu}_{7}$ compounds while it is about 0.80 for $\mathrm{RCu}_{5}$ compounds. Huang et al. ${ }^{12}$ found $c / a$ ratios of $0.82-0.83$ for $\mathrm{Sm}(\mathrm{Co}, \mathrm{Zr})_{7}$ alloys and we also found the same ratios in our $\mathrm{Sm}(\mathrm{Co}, \mathrm{Ti})_{7}$ alloys. ${ }^{13}$ Suzuki et al. ${ }^{14}$ studied $\mathrm{Sm}_{10}(\mathrm{Fe}, \mathrm{V}){ }_{90} \mathrm{~N}_{y}$ and found that the substitution of vanadium for iron in $\mathrm{Sm}_{10}(\mathrm{Fe}, \mathrm{V})_{90}$ alloys gives a great range of stability in the $\mathrm{TbCu}_{7}$-type structure, where this structure can be formed for $5<V<10$. They also found that nitrogenation of the samples improves the magnetic properties including a $(B H)_{\max }$ value of 8.0 MGOe and a $T_{C}$ value of $477^{\circ} \mathrm{C}$ for $\mathrm{Sm}_{10} \mathrm{Fe}_{82.5} \mathrm{~V}_{7.5} \mathrm{~N}_{y}$. Chen et al. ${ }^{15}$ studied $\mathrm{SmCo}_{x}$ alloys by melt spinning and found that the alloys exhibit a single phase $\mathrm{SmCo}_{5}$ and $\mathrm{Sm}_{2} \mathrm{Co}_{17}$ structure for $x=5.0$ and $x=8.8$, respectively, while a three-phase structure $\left(\mathrm{Sm}_{2} \mathrm{Co}_{17}, \mathrm{SmCo}_{5}, \mathrm{SmCo}_{3}\right)$ appears for $5.0<x<8.5$. Recently, studies by Lefever et al. ${ }^{16,17}$ and by Huang et al. ${ }^{12}$ showed that a small amount of $\mathrm{Zr}$ substitution could contribute to the stabilization of the hexagonal $\mathrm{TbCu}_{7}$ structure and improve the magnetic anisotropy in $\mathrm{Sm}-\mathrm{Co}-\mathrm{Zr}$ compounds. An anisotropy field $\left(H_{A}\right)$ value of $180 \mathrm{kOe}$ and a $T_{C}$ value of $750{ }^{\circ} \mathrm{C}$ for $\mathrm{SmCo}_{6.5} \mathrm{Zr}_{0.5}$ have been reported by Huang et al. ${ }^{12}$ The $\mathrm{TbCu}_{7}$-type structure could be indexed according to the $\mathrm{CaCu}_{5}$-type structure with significant deviation of the lattice constants and $\mathrm{x}$-ray peaks' intensities. 


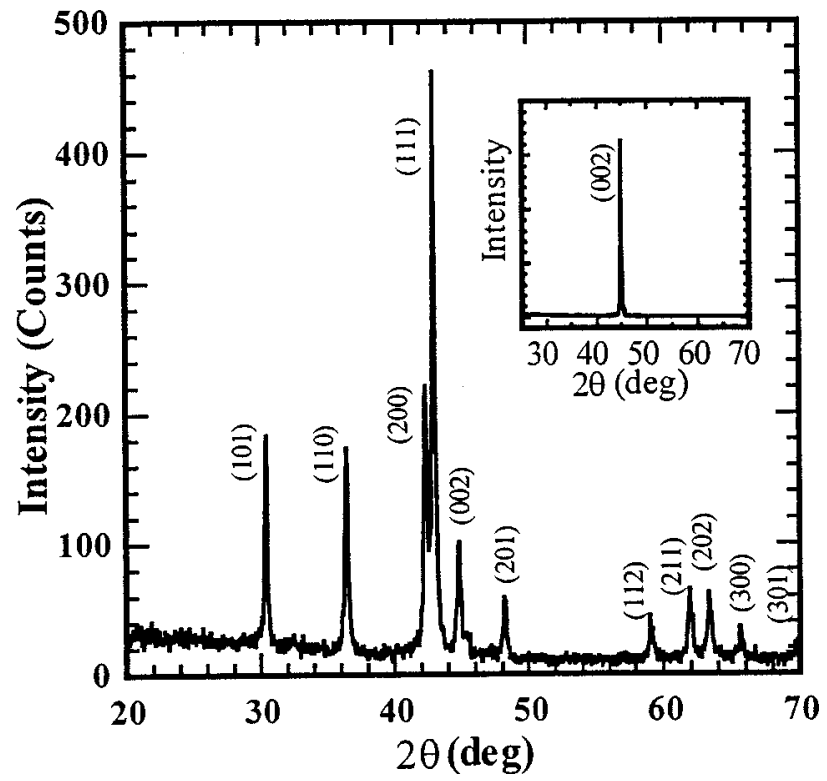

FIG. 1. Typical x-ray diffraction pattern for a $\mathrm{SmCo}_{6.7} \mathrm{Cu}_{0.3}$ alloy. The inset shows a typical $\mathrm{x}$-ray diffraction pattern for the same sample after it has been magnetically aligned.

The aim of this article is to study the effect of $\mathrm{Cu}$ substitution for $\mathrm{Co}$ on the magnetic and structure properties of $\mathrm{SmCo}_{7-x} \mathrm{Cu}_{x}$ alloys.

\section{EXPERIMENTAL PROCEDURE}

Bulk samples of $\operatorname{SmCo}_{(7 \pm \delta)-x} \mathrm{Cu}_{x}$, where $\delta$ is between 0 and 2 and $x=0,0.1,0.2,0.3,0.4,0.5$, and 0.7 , were prepared by arc melting the elements of at least $99.9 \%$ purity in a water-cooled copper boat in a flowing-argon gas atmosphere. The alloys were melted four to five times to insure homogeneity. The phase purity for all the samples was determined by x-ray diffraction using $\mathrm{Cu} K_{\alpha}$ radiation. The magnetization of the alloys was measured by a superconducting quantum interference device (SQUID) magnetometer in the temperature range $25-300 \mathrm{~K}$ and in fields from 0 to 50 kOe. High temperature magnetic measurements were done by a vibrating sample magnetometer (VSM) in the temperature range $300-1273 \mathrm{~K}$.

\section{RESULTS AND DISCUSSION}

Figure 1 shows a typical x-ray diffraction pattern for a $\mathrm{SmCo}_{6.7} \mathrm{Cu}_{0.3}$ alloy. From Fig. 1 we see that the sample crystallizes in the hexagonal $\mathrm{TbCu}_{7}$-type structure. Samples with different $\mathrm{Sm}$ to $(\mathrm{Co}, \mathrm{Cu})$ atomic ratios showed different structures. For example, if the Sm-to- $(\mathrm{Co}, \mathrm{Cu})$ atomic ratios are more than $(1 / 7)$ a hexagonal $\mathrm{CaCu}_{5}$-type structure formed and if the atomic ratio is less than (1/7) a hexagonal $\mathrm{Th}_{2} \mathrm{Ni}_{17}$-type structure formed. This is in agreement with other observations by $\mathrm{Khan}^{18,19}$ for $\mathrm{RCO}_{5 \pm x}$. In this article we are interested in alloys with the $\mathrm{TbCu}_{7}$-type structure; therefore, we present the results for the samples with 1:7 composition. All the samples with the 1:7 composition showed the $\mathrm{TbCu}_{7}$-type structure except for $x=0$ where a minor 2:17-type structure appears. X-ray diffraction shows that there is a shift in the peaks with increasing $\mathrm{Cu}$ concen-
TABLE I. Lattice parameters $(a)$ and $(c)$, unit cell volume $(V)$, saturation magnetization $\left(M_{s}\right)$ at $T=300$ and $25 \mathrm{~K}$, and Curie temperature $\left(T_{c}\right)$ of $\mathrm{SmCo}_{7-x} \mathrm{Cu}_{x}$ alloys as a function of copper concentration $(x)$.

\begin{tabular}{ccccccc}
\hline \hline$X$ & $a(\AA)$ & $C(\AA)$ & $V\left(\AA^{3}\right)$ & $\begin{array}{c}M_{s}(\mathrm{emu} / \mathrm{g}) \\
T=300 \mathrm{~K}\end{array}$ & $\begin{array}{c}M_{s}(\mathrm{emu} / \mathrm{g}) \\
T=25 \mathrm{~K}\end{array}$ & $T_{c}\left({ }^{\circ} \mathrm{C}\right)$ \\
\hline 0.0 & 4.935 & 4.010 & 84.576 & 102 & 103 & 770 \\
0.1 & 4.967 & 4.003 & 85.538 & 85 & 86 & 850 \\
0.2 & 4.968 & 4.060 & 85.606 & 84 & 84 & 852 \\
0.3 & 4.974 & 4.060 & 85.817 & 82 & 83 & 828 \\
0.4 & 4.975 & 4.009 & 85.939 & 71 & 72 & 769 \\
0.5 & 4.978 & 4.010 & 86.045 & 61 & 63 & 758 \\
0.7 & 4.981 & 4.011 & 86.159 & 57 & 58 & 760 \\
\hline \hline
\end{tabular}

tration, which is due to the difference in the atomic volume. Table I summarizes the lattice parameters $a$ and $c$ obtained from the x-ray diffraction patterns for different concentrations. It can be seen that there is a small increase in $a$ and $c$. The $c / a$ ratio for these compounds is about $0.81-0.82$ which is in agreement with other values of $0.82-0.83$ by Huang et al. ${ }^{12}$ for $\mathrm{Sm}(\mathrm{Co}, \mathrm{Zr})_{7}$ alloys and our same values for $\mathrm{Sm}(\mathrm{Co}, \mathrm{Ti})_{7}$ alloys. ${ }^{13}$ The unit cell volume $V$ obtained from the lattice parameters $a$ and $c$ are listed in Table I. It can be seen from the table that there is a volume expansion by substituting $\mathrm{Cu}$ for $\mathrm{Co}$; this expansion is due to the larger atomic volume of $\mathrm{Cu}$, which is in agreement with our observations for other alloys. ${ }^{20}$ Samples for magnetic anisotropy studies were prepared by mixing a fine powder of diameter $<38 \mu \mathrm{m}$ with 5-min epoxy on a glass sample holder and then aligning in a magnetic field of $20 \mathrm{kOe}$ for about $1 \mathrm{~h}$. The inset of Fig. 1 shows a typical x-ray diffraction pattern for the $\mathrm{SmCo}_{6.7} \mathrm{Cu}_{0.3}$ alloy. From this figure we see that the sample, after alignment, shows the (002) peak only indicating a uniaxial magnetocrystalline anisotropy. X-ray diffraction measurements on other aligned samples showed the same results. Magnetic measurements on aligned samples showed that the magnetization in the direction parallel to the aligning field is much higher than that along the direction perpendicular to the aligning field. Figure 2 shows a typical initial magnetization curve for $\mathrm{SmCo}_{6.6} \mathrm{Cu}_{0.4}$ measured at a temperature of $25 \mathrm{~K}$ using the SQUID magnetometer. This figure indicates that the sample is magnetically ordered. Magnetic measurements for other samples showed that all the samples studied are magnetically ordered and the magnetization depends on the $\mathrm{Cu}$ concentration. We find the saturation magnetization by using the law of approach to saturation, by plotting $M$ versus $1 / H$ and extrapolating $M$ to $(1 / H)=0$. The saturation magnetization values for the samples measured at 300 and $25 \mathrm{~K}$ are listed in Table I. It is clear from the table that the saturation magnetization decreases with increasing $\mathrm{Cu}$ concentration, $(x)$, which is due to the replacement of magnetic element $(\mathrm{Co})$ by a nonmagnetic element $(\mathrm{Cu})$. The deviation of the dependence of $M_{s}$ on $x$ from linear dependence can be due to experimental error and/or the estimation of $M_{s}$ by extrapolation. The magnetization as a function of temperature is measured with a VSM under an applied field of $3 \mathrm{kOe}$ for all the samples. Table I also gives the dependence of $T_{C}$ on $\mathrm{Cu}$ concentration. The Curie temperature increases with $x$ reaching a maximum at $x=0.2\left(T_{C}\right.$ 


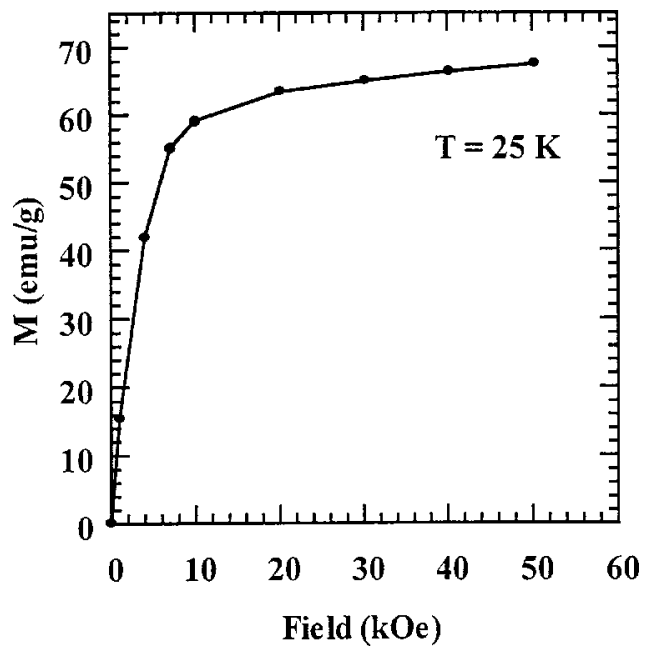

FIG. 2. Typical initial magnetization curve for a $\mathrm{SmCo}_{6.6} \mathrm{Cu}_{0.4}$ alloy measured at a temperature of $25 \mathrm{~K}$.

$=852^{\circ} \mathrm{C}$ ) then decreases with $x$ as can be seen from the table. The maxima in $T_{C}$ and $c / a$ occur at the composition $x=0.2$. The nonmonotonic dependence of $T_{C}$ and $c / a$ on $x$ remains to be understood. This maximum value for $T_{C}$ is higher than that of the $\mathrm{SmCo}_{5}$ compound $\left(T_{C}=750^{\circ} \mathrm{C}\right)$.

\section{CONCLUSIONS}

Samples of the form of $\mathrm{SmCo}_{7-x} \mathrm{Cu}_{x}(x=0,0.1,0.2$, $0.3,0.4,0.5$, and 0.7 ) have been prepared and studied. X-ray diffraction shows that these alloys form the hexagonal $\mathrm{TbCu}_{7}$-type structure. We find that the hexagonal $\mathrm{TbCu}_{7}$-type structure cannot be formed at large values of $x(x \geqslant 0.8)$. X-ray diffraction on magnetically aligned samples show that these samples have uniaxial anisotropy. The lattice parameters $(a$ and $c$ ) are dependent on the $\mathrm{Cu}$ concentration. The unit cell volume is found to increase with $x$. We find that the saturation magnetization decreases with $x$ at room temperature and at a temperature of $25 \mathrm{~K}$. We find that Curie temperature increases with $x$ reaching a peak at $x=0.2\left(T_{C}=852^{\circ} \mathrm{C}\right)$ then decreases with $x$. These properties are promising for high temperature permanent-magnet applications.

\section{ACKNOWLEDGMENTS}

The authors would like to thank Jordan University of Science and Technology, the US Department of Energy, DARPA, US Air Force Office of Scientific Research, and the Israeli Ministry of Infrastructure for financial support.

${ }^{1}$ W. E. Wallace, Prog. Solid State Chem. 16, 127 (1985).

${ }^{2}$ T. H. Jacobs, K. H. J. Buschow, G. F. Zhou, X. Li, and F. R. de Boer, J. Magn. Magn. Mater. 116, 220 (1992).

${ }^{3}$ J. M. D. Coey, H. S. Sun, J. Magn. Magn. Mater. 87, L251 (1990).

${ }^{4}$ Z. Xia-Ping, R. J. Radwanski, F. R. deBoer, T. H. Jacobs, and K. H. J. Buschow, J. Magn. Magn. Mater. 86, 333 (1990).

${ }^{5}$ X. C. Kou, R. Grössinger, T. H. Jacobs, and K. H. J. Buschow, J. Magn. Magn. Mater. 88, 1 (1990).

${ }^{6}$ A. Moller, J. Appl. Phys. 64, 249 (1988).

${ }^{7}$ D. B. De Mooij and K. H. J. Buschow, J. Less-Common Met. 136, 207 (1988).

${ }^{8}$ H. Saito, M. Takahashi, and T. Wakiyama, J. Appl. Phys. 64, 5965 (1988).

${ }^{9}$ Q. F. Xiao, X. K. Sun, D.-Y. Geng, L. Wei, Z.-D. Zhang, and Y. C. Chuang, J. Magn. Magn. Mater. 140-144, 1093 (1995).

${ }^{10}$ M. Katter, J. Wecker, and L. Schultz, J. Appl. Phys. 70, 3188 (1991).

${ }^{11}$ K. H. J. Buschow, A. S. Van Der Goot, Acta Crystallogr., Sect. B 27, 1088 (1971).

${ }^{12}$ M. Q. Huang, W. E. Wallace, M. McHenry, Q. Chen, and B. M. Ma, J. Appl. Phys. 83, 6718 (1998).

${ }^{13}$ J. Zhou, I. A. Al-Omari, J. P. Liu, and D. J. Sellmyer, J. Appl. Phys. 87 (2000), these proceedings.

${ }^{14}$ S. Suzki, S. Suzki, and H. Yamamoto, IEEE Trans. Magn. 31, 902 (1995).

${ }^{15}$ S. K. Chen, M. S. Chu, and J. L. Tsai, IEEE Trans. Magn. 32, 4419 (1996).

${ }^{16}$ A. Lefevre, L. Cataldo, M. Th. Cohn-Adad, C. H. Allibert, and N. Valignat, J. Alloys Compd. 241, 210 (1996)

${ }^{17}$ A. Lefevre, L. Cataldo, M. Th. Cohn-Adad, and B. F. Mentzen, J. Alloys Compd. 255, 161 (1997).

${ }^{18}$ Y. Khan, Acta Crystallogr., Sect. B 30, 861 (1974).

${ }^{19}$ Y. Khan, Phys. Status Solidi A 21, 69 (1974).

${ }^{20}$ I. A. Al-Omari and D. J. Sellmyer, IEEE Trans. Magn. 33, 3850 (1997). 